\title{
¿Qué hay de malo en la eugenesia?
}

\author{
VICTORIA CAMPS \\ Universidad Autónoma de Barcelona
}

RESUMEN. La eugenesia, privada de su sentido peyorativo, se presenta como una posibilidad propiciada por los avances biotecnológicos, que apunta a objetivos terapéuticos, en principio, no reprobables. A la filosofía le compete aclarar los distintos sentidos de eugenesia, poner coto a la fascinación creciente por un supuesto determinismo genético, y mostrar que la distinción entre lo terapéutico y no terapéutico no es estática ni invariable. Todo ello con el objetivo de exigir más rigor en los planteamientos éticos derivados de las distintas prácticas biotecnológicas. No obstante, el filósofo busca una base ontológica más consistente para enfrentarse a problemas como el de la eugenesia. El último libro de Habermas es un ejemplo de ello constituyendo un rechazo de la «eugenesia liberal» que es vista como una amenaza a la integridad de la persona y a su autocomprensión como ser libre. Este artículo pone en cuestión que el recurso a la ontología sea el mejor método para abordar los problemas de la bioética, cuya solución no depende tanto de una determinada concepción de la especie humana, como de la capacidad de hacer un uso responsable de la libertad.
Abstract. Eugenics, deprived of its pejorative sense, can be viewed as a way favoured by biotechnology to serve therapeutical purposes which cannot be condemned for what they are. It concerns to philosophy to make clear the different meanings of eugenics, to put a limit to the increasing fascination produced by genetic determinism, and to show that the distinction between therapy and non therapy is not an static but a dynamic distinction. The aim is to requiere more accuracy in facing the ethical problems derived from biotechnological development. Nevertheless, philosophers have been always looking for a firm ontological basis to deal with problems as that of eugenics. The last book of Habermas is an example of it being a rejection of «liberal eugenesics» since it is seen as a threat to the integrity of persons and to their selfunderstanding as free beings. This article brings into question that the ontological resource provides the best method to face bioethical problems, whose solution does'nt depend so much on a precise conception of human species, as on the capacity of humans to use their freedom in a responsible way.

La eugenesia es, etimológicamente entendida, el arte del buen nacer. Nada malo debiera tener, en principio, lo que es bueno por definición, si no fuera porque las palabras son creaciones humanas y arrastran consigo todas las degeneraciones y perversidades de que somos capaces los humanos. La eugenesia no nombra una realidad que ya estaba ahí antes de que el concepto existiera. Nombra una serie de posibilidades nacidas del uso de la técnica y del quehacer humanos. Nacer bien o mal perteneció al reino de lo casual hasta que la ciencia ha sido capaz de controlar la reproducción humana. De igual modo, 
hemos empezado a llamar eutanasia no a la muerte sobrevenida, accidental, sino a la buena muerte porque es querida como tal. Dominar el nacimiento y la muerte, ahí está el mal. Porque es jugar a ser Dios, empeñarse en saber y hacer más allá de lo permitido y en hacerse cargo de los entresijos más escondidos de la naturaleza.

La eugenesia no es más que un ejemplo de los problemas que plantea en general el uso de la tecnología aplicada a las ciencias biológicas y, en especial, a la genética. Parto del supuesto de que cualquiera de tales problemas tiene que ver con la comprensión posmoderna de la libertad, que es a donde acaban remitiendo casi todos los interrogantes éticos de nuestro tiempo. El sentido y el alcance que deba tener la libertad produce mayor desasosiego a medida que su campo de acción se ensancha y el uso de la misma acaricia objetivos que producen escalofríos. Por eso vamos en busca de una teoría que nos diga claramente que ciertas cosas no se deben hacer aunque la técnica permita hacerlas. Buscamos el amparo de una ontología que contribuya a mitigar la incertidumbre y la perplejidad ante las elecciones a las que obligan los avances de la biotecnología. Mi propósito es mostrar que estas teorías nos ayudan poco a resolver los conflictos éticos. Las fronteras de la autonomía humana no se sustentan en cimientos ontológicos, sino en diálogos y consensos democráticos sobre el sentido que queremos dar a la humanidad y el tipo de sociedad que entre todos estamos dispuestos a soportar y construir. La acción moral no es sólo la acción libre, sino la acción responsable, y es hacia el sentido de la responsabilidad hacia donde debemos dirigir el discurso ético. ¿Qué debemos hacer, en concreto, ante las distintas posibilidades técnicas que ofrece la manipulación genética, las cuales tratan de controlar el origen de la vida, tanto para evitar determinadas disfunciones como para realzar ciertas funciones?

He empezado diciendo que la eugenesia es una bella palabra pervertida por el uso y por connotaciones peyorativas. No sólo eso. Si prescindimos del significado puramente etimológico y acudimos al diccionario, vemos que allí se define la eugenesia como la «aplicación de las leyes biológicas de la herencia al perfeccionamiento de la especie humana». Lo primero que habrá que inquirir, para discurrir razonablemente sobre la cuestión, es si la definición es ajustada a las posibilidades científicas y técnicas reales. Para algunos científicos, decididamente no lo es. Consideran una aberración hablar de eugenesia como actuación sobre una población, ya que sólo es posible actuar sobre una persona o una familia. La idea de cambiar la especie es un puro disparate ${ }^{1}$. Si queremos, pues, seguir adelante, habrá que prescindir, por el momento, de la definición

${ }^{1}$ Así, Josep Egozcue afirma con rotundidad que «la eugenesia es imposible, porque la eliminación de individuos afectos no disminuye la frecuencia del gen en la población, y para incrementar la frecuencia de genes que se consideran «favorables» hay que recurrir a una endogamia forzada, que además favorecería la aparición de recesivos no deseados y es inaceptable en un Estado democrático. En segundo lugar, porque la genética tiende siempre a la media, lo que hace que en los organismos con reproducción sexual sea imposible fijar los genotipos que se 
canónica, o más popular, para referirnos a otra más rigurosa y operativa. A tal propósito, quizá el mejor punto de partida sea la distinción generalmente aceptada entre una eugenesia negativa y una eugenesia positiva. Es cierto que no hay total unanimidad entre los autores a la hora de clasificar las distintas prácticas en ambos tipos de eugenesia. En líneas generales, la eugenesia negativa está constituida por los procedimientos dirigidos a corregir defectos genéticos, mientras la eugenesia positiva consistiría en procedimientos destinados a evitar o disminuir el riesgo de la transmisión de patologías hereditarias, en el sentido más amplio imaginable de la palabra «patología» ${ }^{2}$. Estarían entre las prácticas de eugenesia positiva la selección de gametos para evitar enfermedades relacionadas con el sexo, como la hemofilia, la selección de embriones in vitro tras un diagnóstico de preimplantación, el recurso a gametos o embriones donados, la ingeniería genética o la terapia génica. Todos estos procedimientos admiten variantes y aplicaciones diversas según sea la finalidad que se persiga. Así, la selección embrionaria previa a la implantación en la reproducción artificial puede desechar los embriones patológicos o los embriones «no deseables», como es el caso en la selección de sexo, la cual, a su vez, puede tener un objetivo terapéutico, como la eliminación de la hemofilia, o puede querer satisfacer el capricho de unos padres que prefieren tener un niño y no una niña, o viceversa. La técnica de selección de embriones sanos ha sido utilizada asimismo para implantar aquellos embriones compatibles con otro niño de la misma familia con el fin de realizar posteriormente un trasplante y curar una enfermedad grave ${ }^{3}$. Es así que pasar del método estrictamente terapéutico a lo que viene en llamarse, quizá exagerada e imprecisamente, mejoramiento de la especie, parece una tendencia perfectamente imaginable. El filósofo Hans Jonas sin duda se hace eco de dicha tendencia al llamar eugenesia negativa al «control de apareamiento que intenta evitar la transmisión de genes patógenos o nocivos de cualquier otro modo apartando a sus portadores de la reproducción», y eugenesia positiva a la «selección genética humana planificada con el objetivo de mejorar la especie» ${ }^{4}$. De esta forma se quiere distinguir el procedimiento con fines terapéuticos del que no tiene tales fines, sino otros más calificables como «perfeccionistas», ya que de lo que se trata no es de suprimir caracteres hereditarios indeseables, sino de optimizar los deseables. En un caso, pues, lo que se busca es reparar un error genético; en el otro,

consideren «mejores» en un momento dado» (Medicina predictiva y discriminación, Fundació Víctor Grifols i Lucas, Barcelona, 1999, p. 72; también la ponencia publicada en Ética y genética, Documentos 60/2002, Real Patronato sobre Discapacidad, Ministerio de Trabajo y Asuntos Sociales, Madrid, 2002).

${ }^{2}$ Carlos Romeo Casabona indica que son medidas de eugenesia negativa los anticonceptivos, la esterilización y el aborto, y medidas de eugenesia positiva, las técnicas de reproducción asistida, la terapia génica o la ingeniería genética (Del gen al derecho, Universidad Externado de Colombia, Colombia, 1996, p. 260).

Cf. Carlos Romeo Casabona, ibid., pp. 240 y ss.

${ }^{4}$ Hans Jonas, Técnica, medicina y ética, Barcelona, Paidós, 1997, pp. 115 y 118. 
mejorarlo. Precisemos de momento que la tal mejora no tiene por qué hacernos pensar sólo en la procreación de niños «superiores» (supermanes o mujeres maravillosas, para utilizar el título del libro de John Harris), sino en insertar o suprimir genes que permitan combatir las infecciones, destruir los agentes cancerígenos o retrasar el envejecimiento.

En principio, las clasificaciones debieran tener el objetivo de aclararnos las cosas para poder analizarlas y manejarlas mejor. Pero la realidad siempre es mucho más compleja. De entrada, los procedimientos eugenésicos, positivos o negativos, plantean, por lo menos, dos interrogantes serios. Ya hemos visto que el primero de ellos tiene que ver con las posibilidades reales de la manipulación genética, por lo que hace a sus fines terapéuticos que aún son muy escasos, y, más especialmente, por lo que hace a eso que, en términos generales, viene en llamarse optimización de la especie. Si es cierto que la selección embrionaria permite ya evitar la transmisión de algunas enfermedades, la idea de mejorar la especie es, hoy por hoy, un puro disparate y posiblemente lo seguirá siendo en el futuro. Aunque el determinismo genético es un agarradero tentador y está ocupando el lugar de otros determinismos hoy periclitados, cualquier análisis responsable y riguroso del tema no puede dejar de considerar seriamente no sólo qué es capaz de hacer realmente la biotecnología, sino el hecho indiscutible de que los genes no constituyen el todo de la persona y, en consecuencia, la modificación genética sería sólo una de las variables que entran en juego en la formación de un individuo. Cuando, simplificando en exceso, damos a entender que la clonación embrionaria incluye la posibilidad espeluznante de hacer individuos idénticos, se nos recuerda de inmediato que los gemelos monozigóticos son individuos con información genética idéntica sin que, por ello, las personalidades de uno y otro acaben siendo exactamente iguales. La identidad de los genes no implica la identidad de las personas que los poseen. El ser humano no es sólo naturaleza, sino cultura. Aun cuando llegaran a identificarse el gen de la inteligencia, de la belleza o de la honradez (hipótesis que, hoy por hoy, es pura fantasía, lo que no impide que se especule y se frivolice con ella en los medios de comunicación), esos genes por sí solos no serían determinantes de las cualidades intelectuales, estéticas o morales del individuo. Estamos, pues, ante un primer malentendido que puede pervertir de entrada todo un planteamiento erróneo por mezclar la ciencia que merece tal nombre con lo que sólo es ciencia ficción.

Si la fe en el determinismo científico - genético, en este caso- es un obstáculo cada vez más frecuente para entender y presentar bien los problemas, el otro impedimento radica en la presunción de que las palabras nombran realidades estáticas, por lo que la mejor forma de hacernos cargo de una cuestión es tratando de clasificar la realidad para, de esta forma, poder juzgarla y colocar a cada cosa en su sitio. Acabamos de ver que la clasificación de la eugenesia en negativa y positiva dista mucho de ajustarse a una realidad que es en sí misma mucho más compleja. Una forma fácil de querer acabar con el problema 
ético que parece plantear la eugenesia sería la que consiste en dar la bendición ética a la eugenesia terapéutica condenando, en cambio, a la eugenesia perfeccionista. Está bien - decimos - que haya una selección embrionaria con el fin de evitar el sufrimiento que produce tener un hijo con síndrome de Down. Pero estaría mal la modificación de caracteres hereditarios con el fin de satisfacer el gusto o el capricho de unos padres que desean tener hijos con determinados rasgos físicos o de carácter. Si, hoy por hoy, cuando las técnicas genéticas están aún en pañales, esta distinción puede sernos útil, dado que las posibilidades de manipulación genética, y sobre todo de conseguir fines ciertos con ella, son todavía escasas, no ocurrirá lo mismo cuando, como es previsible, la oferta técnica sea mucho más amplia. Lo terapéutico, las patologías, no son cosas tan fáciles de identificar como lo son los perros o los árboles. Las barreras entre lo patológico y lo anómalo o no deseable por la razón que sea no son estáticas, sino que cambian con los tiempos y de acuerdo con las necesidades, las preferencias subjetivas, los intereses económicos o el nivel de bienestar social alcanzado. Las enfermedades aumentan a medida que lo hace la capacidad humana de curarlas. El malestar psíquico que hasta ayer no tenía ni siquiera nombre que lo designara, hoy tiene una sintomatología relativamente precisa y hay psicólogos y psiquiatras dispuestos a tratarlo. No aceptamos ya que los males del alma no sean tan graves como los corporales. Lo que, por lo menos, plantea la duda de que el afán perfeccionista de los padres de querer lo mejor para sus hijos pueda calificarse sin más de empresa inaceptable. Si es bueno tratar de evitar tener un hijo hemofílico, ¿por qué no habría de serlo querer que nuestro hijo sea bien parecido, longevo o inteligente, suponiendo que pudiera lograrse?

Parece que la función de la filosofía es analizar en clave ontológica problemas como los que aquí se plantean. ¿Es legítimo modificar genéticamente al ser humano? Y si no lo es, ¿en qué se sustenta la ilegitimidad? ¿Qué es o qué se espera que sea un ser humano, a fin de cuentas? Los cambios genéticos son cambios permanentes e irreversibles. ¿No es una injusticia con las personas y con la humanidad en general proceder a realizar tales cambios? Es lo que se pregunta John Harris en el libro recién mencionado: «iPodríamos cometer una injusticia con las personas al modificar sus susceptibilidades genéticas y no podrían en justicia buscar venganza?». $\mathrm{O}$ «ipodríamos cometer una injusticia con la humanidad en general al crear una nueva subespecie de superseres, o incluso si llegásemos a cambiar la humanidad al completo por algo que creyésemos ser mejor?» ${ }^{5}$. Más allá de que preguntas tan generales no sean pertinentes por científicamente infundadas, hay en ellas dos temores que sí es posible trasladar a las técnicas más concretas de selección embrionaria: 1) el temor de que es injusto experimentar con personas, especialmente cuando no pueden oponerse a tales experimentos porque aún no han nacido; 2) la convicción - discutible - de que la irreversibilidad del cambio producido por

\footnotetext{
${ }^{5}$ John Harris, Supermán y la mujer maravillosa, Madrid, Tecnos, 1998, pp. 198-199.
} 
la manipulación genética añade un agravante cualitativamente distinto a cualquier otro tipo de manipulación o experimento realizado con humanos.

Cuando nos planteamos un problema ético - cualquier problema acerca del ise debe o no se debe hacer?-, intentamos hacerlo desde la perspectiva de los principios fundamentales aceptados como rectores de la conducta humana. ¿Qué principio se vulnera? parece ser el meollo de la cuestión. El principio formulado por Kant como imperativo categórico puede ser el mejor punto de partida para juzgar la bondad o maldad, la justicia o la injusticia de la eugenesia o de cualquier manipulación con seres humanos: «Actúa de tal manera que trates a la humanidad, tanto en tu persona como en la persona de cualquier otro, siempre como un fin y nunca únicamente como un medio». Es decir, no manipules al otro en tu propio beneficio, pues el otro es un ser humano que merece siempre el respeto debido a cualquier otro ser humano. Respetar la dignidad del otro implica no tratarlo como si fuera una cosa al servicio de los propios intereses. De ahí que, cuando la manipulación es inevitable - como le ocurre, sencillamente, a cualquier enfermo cuando se pone en manos de un médico-, el respeto al otro se exterioriza en la exigencia de recabar su consentimiento antes de ser sometido a esa manipulación inevitable. Un requisito, sin embargo, que no sirve en nuestro caso, puesto que no es posible ejecutarlo con quienes aún no han nacido, que son quienes han de ver modificados sus genes. A los padres no les es dada la posibilidad de preguntarle al hijo que va a nacer si quiere nacer con unas características o con otras, como tampoco pueden preguntarle si quiere o no ser engendrado. Los padres deciden en tal caso por sí mismos y, sobre todo, por su descendencia. La pregunta es: ¿cabe que decidan sin límites? Y si deben imponer ciertos límites a sus deseos, ¿qué razones hay que los justifiquen?

Conviene aclarar algo antes de proseguir. Hemos dicho que tanto si se trata de la eugenesia llamada negativa como de la positiva partimos de la hipótesis de que lo que se busca es el bien de la descendencia. Excluimos de entrada el experimento por el experimento, para producir seres híbridos o quimeras, incluso como mera especulación sometida a análisis ético. Excluimos las salvajadas que decían perpetrar los nazis para eliminar determinados grupos humanos. Es injusto y éticamente condenable sin más utilizar a los seres humanos como cobayas ${ }^{6}$. No hace falta detenerse en ello buscando paliativos o matices. Nos referimos ahora únicamente a la eugenesia practicada con buena intención, con la intención de mejorar, en todos los sentidos imaginables de la palabra «mejorar», la herencia genética de ciertos individuos. Desde tal

${ }^{6}$ Conviene distinguir aquí entre la manipulación genética de la línea somática y la manipulación de la línea germinal. La primera se limita a intervenir en las células de un individuo concreto sin incorporar las modificaciones en su configuración genética, mientras la segunda altera el genoma del individuo y de su prole produciendo un ser con una identidad distinta. Es el caso del «oncoratón», un ratón alterado genéticamente para que manifieste un oncogén determinado proporcionando así un instrumento valioso para la investigación del cáncer. Cf. John Harris, Superman y la mujer maravillosa, Madrid, Tecnos, 1998, pp. 32-33 y 222. 
supuesto, los límites que coartan la libertad de los progenitores impidiéndoles proyectar en sus hijos la optimización de sus deseos deberá tener que ver con algo que por sí mismo sea inaceptable, bien porque se encuentra en la línea de los principios básicos que nos hablan de la dignidad absoluta de la persona, bien porque permiten augurar consecuencias poco seguras y, por lo tanto, éticamente dudosas. No basta aducir sólo el argumento de que la modificación genética no puede tener en cuenta el punto de vista de los que nacerán con tal modificación, vulnerando, por lo tanto, el principio de autonomía, pues si de eso se tratara, la mera decisión de procrear merecería el mismo reproche que la manipulación genética. Tampoco a los hijos se les consulta antes de decidir traerlos al mundo. ¿Qué es, pues, lo inaceptable en la selección de los caracteres hereditarios con vistas a la reproducción?

La ética de las consecuencias quizá sería suficiente para poner vetos a un uso de la libertad excesivamente arbitrario o indiscriminado. En pocos casos de manipulación genética se puede actuar con la certeza de que el resultado que se busca se dará y sin efectos indeseables. En el supuesto de que lo que se persigue son objetivos claramente terapéuticos o la supresión de disfunciones, pienso que la intervención genética no plantea más problemas que otras intervenciones clínicas de efectos igualmente inciertos o dudosos. Únicamente habría que valorar las ventajas y desventajas para la persona afectada, y decidir en consecuencia. Ahora bien, cuando hablamos de intervenciones genéticas dirigidas a ensalzar funciones, el cálculo de las consecuencias es tanto ética como científicamente mucho más problemático, porque las consecuencias son menos previsibles y porque no podemos evitar consideraciones que nos llevan al terreno de los derechos y los principios. Si los criterios consecuencialistas son útiles cuando lo que se buscan son objetivos terapéuticos, dichos criterios se muestran totalmente insuficientes si pensamos en objetivos dudosamente terapéuticos. John Harris, en la obra citada, aplica la perspectiva consecuencialista al problema de la eugenesia en el más amplio sentido, es decir, presumiendo que las técnicas permitan introducir genes nuevos y modificar el genoma humano produciendo «una nueva casta». Cualquiera de las ventajas imaginables bajo tal supuesto ofrece, al mismo tiempo, un cariz desventajoso, el más destacable de los cuales es la inevitable injusticia social que produciría la creación de una casta de individuos privilegiados más inmunes que el resto a determinadas enfermedades y con una esperanza de vida mayor, lo cual sin duda llevaría a esa nueva casta a confinar la procreación entre ellos. Sin entrar ahora en la observación casi obvia de que cualquier cálculo de ventajas y desventajas de aplicaciones biotecnológicas como la que estamos considerando conduce a consideraciones y previsiones más bien peregrinas y poco fundadas en una realidad que aún está muy lejos de poderse conseguir, la conclusión de Harris es favorable a dar vía libre a la biotecnología pues, a fin de cuentas, piensa que las ventajas superarían a las desventajas siempre que consiguieran curar algunos de los males que hoy por hoy son incurables. Por mi parte, y sin 
compartir totalmente el optimismo de Harris, pienso, como he dicho hace un momento, que un análisis de la ingeniería genética desde la perspectiva consecuencialista sólo es aplicable a procedimientos con fines terapéuticos y no tiene otro apoyo en el que sustentarse que el método estadístico ${ }^{7}$.

Es esta dependencia de la contingencia de lo empírico lo que nos deja inquietos ante la ética consecuencialista. Por eso buscamos una base más sólida para resolver los problemas éticos. ¿Hay algo en la línea no de las consecuencias sino de los principios que fuerce a decir no a todas estas técnicas que, de un modo u otro, instrumentalizan la vida humana? ¿Podríamos afirmar que ciertas modificaciones son injustas con los individuos directamente afectados y con la humanidad en general? ¿La ingeniería genética pone en peligro la integridad de la especie humana? Sabemos que la especie humana ha experimentado una larga y compleja evolución y transformación. El proceso de hominización - escribe el filósofo de la complejidad, Edgar Morin ${ }^{8}$ - ha sido «un juego de interferencias que presupone la existencia de acontecimientos, eliminaciones, selecciones, integraciones, migraciones, fracasos, éxitos, desastres, innovaciones, desorganizaciones, reorganizaciones». En ese proceso se han producido una serie de mutaciones genéticas que dieron lugar a la aparición del lenguaje o incluso al desarrollo de aptitudes estratégicas para defenderse de los animales carnívoros, como la atención, la tenacidad, la audacia, el señuelo, la trampa o el acecho ${ }^{9}$. Tal explicación — añade Morin- conduce al hundimiento del antiguo paradigma que oponía la naturaleza a la cultura, para afirmar, en cambio, que «el hombre es un ser cultural por naturaleza porque es un ser natural por cultura». No obstante, y aun estando de acuerdo con dicha perspectiva de transformación progresiva de la especie, parece que hay algo nuevo y diferente en la posibilidad no de que la mano del hombre o la técnica modifiquen a la naturaleza en general, sino en el hecho de que se pueda «programar» la existencia de futuros individuos. De un modo u otro, no conseguimos librarnos del pecado de Prometeo. Ante cada nuevo paso de la técnica se plantea de nuevo la pregunta secular: iquién es el hombre para cambiar el curso de lo natural? En este caso: ¿quién es el hombre para intervenir en los genes hasta el punto de llegar a alterar el patrimonio genético? La proclamación del genoma humano como patrimonio de la humanidad es la primera respuesta jurídica o política a tales interrogantes. El Consejo de Europa, en el «Proyecto de Convenio sobre la protección de los derechos

${ }^{7}$ Por otra parte, aunque la idea de dar lugar a una «nueva casta» puede entenderse como uno de esos ideales de mejora de la especie que científicamente parecen ser un disparate, no lo es tanto si pensamos en otros intentos que sí son posibles y problemáticos, como el de eliminar, en la fase embrionaria, a individuos que puedan ser portadores de genes de riesgo, para evitar así patologías como el Alzheimer. Esa exclusión impediría la reproducción de individuos que no ofrecieran garantías de salud a corto y largo plazo. Por lo tanto, acabaría seleccionando una «nueva casta» de individuos sanos.

${ }^{8}$ Edgar Morin, El paradigma perdido, Barcelona, Kairós, 1974, p. 67.

${ }^{9}$ Ibid., pp. 72, 84. 
humanos y la dignidad de la persona respecto a las aplicaciones de la biología y la medicina» (1995), proclama que «El genoma humano es un componente fundamental del patrimonio común de la humanidad y necesita ser protegido para salvaguardar la integridad de la especie humana, como un valor en sí mismo, y la dignidad y derechos de cada uno de sus miembros». ¿Podemos justificar filosóficamente dichas afirmaciones?

El último libro de Habermas entra de lleno en tal planteamiento con la intención de llevarnos hasta su fundamento ontológico. El futuro de la naturaleza humana. ¿Hacia una eugenesia liberal? constituye una crítica radical a una vía libre hacia la eugenesia. La libertad, tal como tendemos a entenderla en la época posmetafísica, como mera ausencia de normas, puede generar comportamientos éticamente reprobables. Al filósofo le corresponde pensar y razonar los límites de una autonomía que con demasiada frecuencia se confunde con la pura arbitrariedad. Lo que Habermas le reprocha a la filosofía no es tanto la inhibición política o legislativa, como lo que, a su juicio, le correspondería hacer al filósofo: elaborar una teoría que explique los fundamentos ontológicos que nos obligan a poner límites a la eugenesia. Habermas busca ese respaldo ontológico que dé razones para vetar ciertos desarrollos y aplicaciones biotecnológicos.

Estoy de acuerdo con la mayor: la filosofía posmetafísica ha renunciado a plantearse la pregunta por la «vida recta». Renuncia incomprensible, en la opinión de Habermas, si comparamos el quehacer filosófico con el psicoanalítico. Los psicoanalistas se enfrentan a la enfermedad psíquica y procuran tratarla clínicamente porque ven en la sinrazón la pérdida de un modo de existencia específicamente humano. ¿Por qué el filósofo —el filósofo moralha dejado de preocuparse por aquellos comportamientos y prácticas que pueden llevar a consecuencias similares, es decir, a la pérdida de lo específicamente humano? La «vida recta» por la que hay que luchar — sigue argumentando Habermas - no es algo revelado ni «dado»: está en el lenguaje, en ese fruto de la intersubjetividad o del esfuerzo compartido. Me remito a su texto: «El logos del lenguaje se sustrae a nuestros controles y, sin embargo, es el medio en el que nosotros, sujetos aptos para el lenguaje y la acción, nos entendemos. Es "nuestro" lenguaje. La incondicionalidad de la verdad y la libertad es un presupuesto necesario de nuestras prácticas, pero, más allá de ser constituyentes de "nuestra" forma de vida, carecen de toda garantía ontológica. Por lo tanto, la autocomprensión ética "recta" ni es revelada ni "dada" de cualquier otra manera. Sólo puede ganarse en un esfuerzo común. Desde esta perspectiva, lo que hace posible nuestro ser sí mismo parece más un poder transubjetivo que un poder absoluto» ${ }^{10}$. Después de un párrafo como éste, que he transcrito en su totalidad porque me propongo exprimirlo al máximo, lo consecuente sería, a mi juicio, exigir una acción política o legislativa, unas recomendaciones éticas, que contribuyeran a construir lingüística y socialmente esa vida recta

\footnotetext{
${ }^{10}$ Jürgen Habermas, El futuro de la naturaleza humana, Barcelona, Paidós, 2002, p. 23.
} 
que es patrimonio de todos. Pero a Habermas no parece satisfacerle tal conclusión. El artífice de la ética discursiva busca otros fundamentos más allá del lenguaje y la intersubjetividad que nos constituyen como seres humanos para pronunciarnos sobre la justicia y el bien. La vida recta, vendrá a decir, tiene que poner límites a la eugenesia liberal por una cuestión de principio: porque atenta contra la integridad de la naturaleza humana. Mi pregunta es: ise sustenta ese «argumento ontológico» y es necesario para justificar unos límites que sin duda hay que poner a la libertad?

Expliquemos un poco más el desarrollo teórico de Habermas. Hay, a su juicio, dos razones fundamentales en contra de la eugenesia liberal: 1) la eugenesia afecta a los descendientes de una manera irreversible; 2) la eugenesia atenta contra «la indisponibilidad de lo natural»o «los fundamentos genéticos de nuestra existencia corporal». No me detengo en el primer punto por lo que he dicho hace un momento: tan irreversible es la decisión de procrear pasando por la intervención genética o por la selección embrionaria como la decisión de procrear sin más. Nuestros hijos podrán pedirnos cuentas de haberlos hecho de tal o cual manera, pero también podrían pedirnos cuentas de haberlos traído al mundo sin más. ¿Dónde está la diferencia?

La diferencia la pone Habermas en ese matiz nada liviano que distingue el procrear natural del procrear programado. La diferencia está en que lo genético ha sido hasta ahora «indisponible», casual. Modificarlo significa cambiar radicalmente esa condición: lo que no se podía escoger, ahora es y será cada vez más materia de elección. Lo cual hay que reconocer que, en principio, no es muy distinto del cambio experimentado a raíz del aumento de técnicas terapéuticas o no tan terapéuticas, como es el caso de las intervenciones con finalidades estéticas. Mientras no hubo vacunas para combatirlas, la tuberculosis o la viruela fueron mortales. Hasta hace muy poco, uno no tenía más remedio que cargar con el físico que le había tocado en suerte. Hoy casi todo es operable y modificable. Si la técnica permite tantas cosas, ¿por qué ha de preocuparnos especialmente el paso de lo indisponible a lo disponible permitido por la biotecnología?

La clave de la respuesta, para Habermas, está en que precisamente ese paso de lo que era indisponible a algo disponible afecta a la identidad de la especie. El dominio sobre lo genético es más grave que todas las formas de dominación sobre las enfermedades físicas, psíquicas o morales. La intervención en los genes atenta contra la continuidad de la humanidad, cosa que no ocurre cuando se interrumpe, gracias a la técnica, el curso de una enfermedad cualquiera, ni siquiera cuando se interrumpe el embarazo. Habermas hace especial hincapié en ello: la diferencia entre la interrupción del embarazo y la manipulación genética es precisamente ésta: «la manipulación de los genes afecta a cuestiones de identidad de la especie; y la autocomprensión del ser humano como perteneciente a una especie también conforma el lecho de nuestras representaciones legales y morales» ${ }^{11}$. En su opinión, es radicalmente distinto

\footnotetext{
${ }^{11}$ Ibid., p. 37.
} 
interrumpir un embarazo impidiendo un nacimiento, que programar un nacimiento. Es en el hecho de «programar» donde puede quedar afectada la identidad de la especie. ¿Pero en qué sentido?

En el sentido ontológico-moral, pues esa identidad es la base «de nuestras representaciones legales y morales». Al intervenir genéticamente, elegimos libremente lo que hasta ahora fue casual, y quien lo elige no es, evidentemente, la persona afectada, sino sus progenitores. Vuelve el argumento de la autonomía vulnerada, ya que no es posible preguntarle al no nacido. Pero Habermas va más allá: de la vulneración de la autonomía deduce algo así como la pérdida de autonomía del futuro ser o, por lo menos, una amenaza a la libertad que puede hacer de él un ser privado de aquello que otorga identidad moral al ser humano. Piensa que es legítimo augurar el peligro de que los seres nacidos tras la manipulación genética no puedan verse a sí mismos tan libres como los que no tuvieron un origen previamente programado. De donde habría que concluir que, salvo en los casos específicos en que se busca un efecto terapéutico tan claro como el de evitar una enfermedad hereditaria, no podemos tener la seguridad de que la pérdida de un comienzo «indisponible» o «natural» no signifique al mismo tiempo una asimetría insalvable entre el «programador» y el «programado», entre el ser que sencillamente ha «nacido» y el ser que, por el contrario, ha sido «hecho». La vida humana, dicho de otra forma, no debe ser manipulable hasta ese punto. La libertad humana es el nombre que damos a lo incondicionado, a lo que está en nuestras manos elegir o cambiar. Si destruimos ese punto de partida al condicionar los caracteres del futuro ser, ponemos en cuestión la libertad y también la igualdad entre los humanos. La identidad de la especie se rompe en la medida en que la libertad de elegir un plan de vida será más plena y total en unos individuos que en otros. «Por lo que respecta a la libertad ética de llevar una vida propia bajo condiciones de partida orgánicas no elegidas por uno mismo, la persona programada no se encuentra de entrada en situación diferente a la persona engendrada naturalmente. Sin embargo, una programación eugenésica de propiedades y disposiciones deseables provoca reparos morales si fija a la persona afectada a un determinado plan vital, si coarta específicamente su libertad para elegir una vida propia» ${ }^{12}$.

Aun estando de acuerdo con la conclusión a la que llega Habermas —restringir la manipulación genética a objetivos terapéuticos y no permitir los objetivos calificables sólo como «perfeccionistas»-, no me parece que esa conclusión pueda depender del argumento de que lo que peligra con las modificaciones genéticas es la identidad de la especie. Es cierto que la sustitución de lo casual e incontrolable por una cierta programación determinante de ciertos caracteres en la persona futura produce más de una inquietud. Prueba de ello es que hay estudios realizados que indican que los padres de niños nacidos por fecundación in vitro prefieren ocultarles a sus hijos el procedimiento

\footnotetext{
${ }^{12}$ Ibid., p. 84.
} 
al que se sometieron para tenerlos. Temen que el saberse fruto de reproducción artificial provoque en ellos la sensación de que son seres distintos, o temen que esos hijos encuentren en dicho procedimiento, no demasiado habitual por el momento, más de un argumento para el reproche, especialmente si no llegan a reconciliarse del todo con su propia vida. Detengámonos un momento en ese temor y en las razones que pueden explicarlo.

La tesis de Habermas es que el individuo genéticamente programado puede sentir que no es libre de proyectar su vida como lo son los otros seres. ¿Qué motivos tendrá para sentirse distinto? Si el motivo es la simple modificación genética, ese sentimiento no será muy distinto del que puedan tener las personas cuyos padres accedieron a una selección embrionaria previa al nacimiento para evitar, por ejemplo, tener un hijo hemofílico. Incluso, como indica el estudio al que acabo de aludir, el cada vez mayor número de niños nacidos por fecundación in vitro, sin que haya habido en tal procedimiento ningún tipo de ingeniería genética, parece que es proclive a tal sentimiento de extrañeza. La pregunta que hay que hacerse es: ¿tiene fundamento dicho sentimiento? O, volviendo a Habermas, ¿es correcto poner en duda la legitimidad de la modificación genética basándose en la posibilidad de tal sentimiento de pérdida de identidad o incluso el rechazo de una identidad que no se siente como propia? Ese desdoblamiento de la persona entre lo que pudo haber sido y lo que es, debido a que lo «hicieron» así, lo «programaron», ino necesita a su vez de una justificación ulterior? Dicho de otra forma: ¿la «autocomprensión» del individuo no es una construcción social que depende tanto de esas características que preocupan a Habermas como de la forma en que la sociedad las procese y las evalúe? ¿Es legítimo y razonable hacer descansar dicha evaluación en el sentimiento que puedan albergar los seres genéticamente modificados?

La cuestión es grave si consideramos las consecuencias que pueden derivar del «sentirse distinto» y no sólo distinto, sino, de algún modo, «engañado», que es, me parece, lo que Habermas quiere dar a entender. La sensación de injusticia o de fraude - justificado o no-dará lugar a quejas, reclamaciones, denuncias o venganzas, como ya empieza a ocurrir con individuos que no son como hubieran querido ser y encuentran abogados dispuestos a ayudarles a querellarse contra sus progenitores. El argumento de Habermas tendría, pues, dos partes: el nacido tras una manipulación de sus genes no se identifica del todo consigo mismo; luego, tiene derecho a reclamar la identidad que le fue hurtada. La deducción sería convincente si la mayor fuera indiscutible. ¿Lo es?

Varios filósofos - Thomas Nagel, Thomas McCarthy y, de algún modo, también Ronald Dworkin - se han manifestado ya en contra de dicha premisa. Es dudoso - alegan - que los nacidos tras un procedimiento de modificación genética se vean o se experimenten a sí mismos de otra manera que los individuos, digamos, «normales». Su autonomía, dicho de otra forma, no peligra más que la del niño a quien sus padres se empeñan en educar para que sea un campeón olímpico o para que sea violinista. En cualquier caso, la educación 
siempre será un condicionamiento, rectificable sólo hasta cierto punto. Sin duda, la intervención en los genes es irreversible y no puede decirse lo mismo de la educación que, aunque condiciona la personalidad futura, lo hace en menor grado. Ahora bien, ipuede derivarse de tal supuesta irreversibilidad que está seriamente amenazada la autonomía de la persona, que esos seres «programados» podrían dejar de «autocomprenderse como libres e iguales», como afirma literalmente Habermas?

No acabo de ver que la relación de la libertad con lo incondicionado pueda romperse sin más por una intervención previa en los genes que han de constituir, entre otras variables, a un individuo. La hipótesis sería más razonable si lo que se intentara fuera la producción de una especie insólita, un híbrido o una quimera. Pero ya hemos dicho que descartamos tales experimentos como inmorales sin más. En el caso de intentar incluso una eugenesia positiva que optimice determinadas funciones, no sé hasta qué punto cabría concluir que el individuo resultante puede ver coartada la libertad para programar su vida. Y si no es así, ¿en qué motivos podrá apoyarse para reprocharle a nadie su personalidad?

En suma, no veo que la irreversibilidad de la intervención genética constituya una determinación más preocupante que la irreversibilidad de un simple embarazo. Veo, sí, el peligro de que ciertas manipulaciones puedan dar lugar a consecuencias no previsibles. Lo que me lleva a pensar que la inquietud ética habría que situarla más bien en la imprevisibilidad de las consecuencias que en la irreversibilidad o en la indisponibilidad del comienzo - como quiere Habermas-. Las consecuencias de técnicas aún poco contrastadas sí pueden ser terriblemente graves para la vida de una persona. Así pues, habría que concluir que sólo en aquellos casos en que la intervención genética tiene consecuencias ciertas y claramente beneficiosas para la persona, ésta puede considerarse éticamente irreprochable. Con lo cual quizá tengamos que limitarnos a dar la bendición a las prácticas eugenésicas terapéuticas y con garantías, como ya indica la ley ${ }^{13}$.

Volviendo al punto por donde he empezado. La eugenesia liberal, entendida como la ausencia de normas que la controlen, es un mal punto de partida para la ética. Hay que partir del supuesto de que la libertad debe tener unos límites. ¿Por qué razón? No porque la eugenesia amenace nuestra «autocomprensión como seres morales», sino porque muchas consecuencias de las prácticas eugenésicas son aún imprevisibles y plantean cantidad de problemas científicos que desaconsejan su uso. Otra cosa es que queramos plantearnos cómo habría que juzgar éticamente lo que hoy es sólo una especulación sin demasiada base científica. No está mal que la filosofía, por una vez, se adelante a los hechos. Lo que puede ocurrir es que esos hechos no lleguen jamás.

${ }_{13}$ «Estas técnicas podrán utilizarse también en la prevención y tratamiento de enfermedades de origen genético hereditario, cuando sea posible recurrir a ellas con suficientes garantías diagnósticas y terapéuticas y estén estrictamente indicadas» (Ley sobre Técnicas de Reproducción Asistida, art. 1.3). 
¿A qué hay que llamar «eugenesia»? El término es hermoso, decía al principio, y si hoy tiene connotaciones negativas es porque se ha hecho un uso inapropiado del mismo. Si hay que seguir utilizando la palabra, ésta debe perder las connotaciones peyorativas y limitarse a designar los intentos de evitar el nacimiento de niños enfermos. «Eugenesia» debería ser la palabra que designara realmente el buen nacer, el nacer desprovisto de patologías y malformaciones evitables, claramente evitables. Repito que estoy de acuerdo con Habermas en que es tarea del filósofo preguntarse por la «vida recta», y que la tal pregunta debería conducir a una concepción de la libertad menos «liberal» que la que tenemos. La autonomía moral no es la mera ausencia de normas, sino el control razonable sobre uno mismo. Lo que no creo es que, para justificar ese control sobre uno mismo y sobre la sociedad de la que formamos parte, sea preciso echar mano de una ontología de la persona, aunque sea una ontología moral. Estoy con MacIntyre cuando afirma que dicha ontología pertenece a la historia y ya no es posible recuperarla ${ }^{14}$. Aunque la libertad, por oposición a la causalidad física, se defina como lo incondicionado, sabemos que lo incondicionado absoluto no existe para los humanos, por lo que decidir qué condicionamientos pertenecen a nuestra especie y cuáles son meramente culturales, educativos o sociales, distinguir qué influencias ponen en peligro nuestra autocomprensión como seres libres, son cuestiones que pertenecen más bien a la categoría de los pseudoproblemas. ¿O es que habrá que acabar aceptando que es más libre el niño nacido en Kenya y, por lo mismo, condenado casi irremisiblemente a morir de hambre o por falta de medicamentos, que el niño europeo cuyos padres han podido permitirse el lujo de elegir engendrar a un niño y no a una niña? Podemos no estar de acuerdo con la elección del sexo por lo que supone de discriminación de género, pero no porque amenace la autocomprensión moral del individuo en cuestión.

Lo importante es el lenguaje que utilizamos y el discurso —o la opiniónque construimos a partir de tal lenguaje. Ahí sí que la filosofía tiene un ámbito propio: el de clarificar los conceptos exigiendo al mismo tiempo la mayor precisión en el uso de los mismos, sobre todo cuando se trata de términos ambivalentes. Las palabras valorativas son «inconstantes», dijo Hobbes, precisamente porque las creamos como respuesta a ciertas necesidades o perspectivas que pueden cambiar como cambian las costumbres. Seguramente, «eugenesia» es hoy una de tales palabras y no es indiferente que consagremos un significado en lugar de otro. La forma de definirla, al igual que la forma de presentar a la opinión pública las innovaciones biotecnológicas, determinará lo que esa opinión acabe haciendo con todo ello. Desde la perspectiva de la información y la formación de opinión, creo que hay dos cuestiones especialmente preocupantes relacionadas con la selección embrionaria o la manipulación genética prenatal: confundir con la ciencia lo que sólo es fruto de la imaginación, y presentar como problemático lo que no tiene por qué serlo.

\footnotetext{
${ }^{14}$ A. McIntyre, Tras la virtud, Barcelona, Crítica, 1991.
} 
Con respecto al primer punto habría que ser bastante más cautos al considerar todo aquello que suele clasificarse como «eugenesia positiva», cuyo fin se presume que es la optimización de unos individuos o, generalizando indebidamente, de la especie. Más allá del deseo totalmente caprichoso de tener hijos de uno u otro sexo, con ojos azules, altos y rubios, deseos que probablemente no sea difícil llegar a satisfacer, ihay otras supuestas «mejoras» posibles? Los hijos no heredan todos los caracteres genéticos de sus padres y la mayoría de los caracteres heredados son modificables por estar expuestos a influencias sociales, culturales o ambientales diversas. La inteligencia no se desarrolla si no hay un entorno propicio para ello, hablar del gen de la felicidad es una tontería, los rasgos de carácter son susceptibles de ser convertidos en virtudes o vicios, como sabemos desde Aristóteles, en cuanto a la posibilidad de no envejecer, habría que ver primero en qué se concreta para poderla considerar una ventaja. El problema de hablar de un posible «perfeccionamiento de los individuos o de la especie» gracias a la manipulación genética no radica tanto en la subjetividad o relativismo que encierra la idea de perfección, sino en que es una empresa absurda por imposible.

Por lo que hace al segundo punto, que la persona cuyos genes hayan sido modificados se autocomprenda de un modo distinto a la persona «normal», y que ello sea fundamento para futuros reproches, denuncias o querellas, creo que está en nuestra manos entenderlo así y dar vía libre a tales autocomprensiones, o, por el contrario, considerarlas absurdas. No veo un modo mejor de respaldar lo que quiero decir que repitiendo la idea de Habermas citada al principio de este artículo: «la autocomprensión ética "recta" ni es revelada ni "dada"... Sólo puede ganarse con un esfuerzo común», el esfuerzo de la intersubjetividad que crea lenguaje y opinión. Es ese esfuerzo el que ha de ir delimitando qué eugenesia es justificable, qué opciones son puro capricho, y qué especulaciones no merecen consideración ninguna porque no tienen base científica. La voluntad de entender y representarse las cosas correctamente, por otra parte, cerrará el paso a esas temidas reclamaciones de hijos con personalidades manipuladas. Una reacción que no es sino la consecuencia directa de las sociedades demasiado individualizadas, atomizadas y económicamente interesadas en que vivimos, poco dispuestas al diálogo en busca del interés común.

El recurso a la ontología como justificación última de nuestros puntos de vista no es sino la búsqueda de ese confort metafísico que la posmodernidad, con Rorty a la cabeza, ha tenido a bien rechazar. El rechazo no es fácil de aceptar porque redunda en acrecentar la perplejidad, la incertidumbre y el miedo que producen las innovaciones tecnológicas. Frente a ello, siempre es más cómodo echar mano de una teoría que avale nuestras decisiones. Me referiré de nuevo a la propuesta de Edgar Morin de olvidarnos del paradigma que contrapone lo natural a lo cultural, para pensar que somos seres «biosocioculturales», lo cual significa que «las estructuras de orga- 
nización cognoscitivas, lingüísticas y prácticas que emergen a través de los nuevos desarrollos del cerebro, son estructuras innatas que reemplazan los programas estereotipados o instintos. En lo sucesivo quedarán inscritas en la herencia genética, mientras que un gran número de comportamientos estereotipados desaparecerán, pero dichas estructuras de organización sólo adquirirán un carácter operativo a partir de la educación sociocultural y en un medio social complejificado por la cultura» ${ }^{15}$. El hombre es un ser inacabado - homo is quammodo omnia - y es esa falta de realización final lo que le hace un ser libre. ¿Puede una programación genética suprimir esa libertad? El mismo control de natalidad ino fue igualmente visto en su momento como una programación inaceptable? Como decía, cada novedad técnica nos recuerda el mito de Prometeo.

No es la especie, sino la «condición» humana lo que tenemos la obligación de preservar. La condición humana es maleable y transformable, pero no debe ser transformada en su contrario que sería lo inhumano. Lo que nos hace falta es un criterio de humanidad que sirva de pauta para distinguir las manipulaciones genéticas aceptables de las que no lo son. Ese criterio nos lo dio Kant con su imperativo de la dignidad. Y ha sido reformulado por Hans Jonas pensando precisamente en los problemas que ahora nos ocupan: «Obra de tal modo que los efectos de tu acción sean compatibles con la permanencia de una vida humana auténtica en la Tierra». Que también puede expresarse así: «No pongas en peligro las condiciones de la continuidad indefinida de la humanidad en la Tierra». O de esta manera: «Incluye en tu elección presente, como objeto también de tu querer, la futura integridad del hombre» ${ }^{16}$.

Para que la pervivencia de una vida humana auténtica o íntegra en la tierra sea posible, habrá que desarrollar una serie de valores o virtudes —explica el mismo Jonas- especialmente importantes para el mundo del mañana. Dichas virtudes serían tratar de recabar la máxima información sobre las consecuencias del actuar colectivo, el temor a perder lo que hemos logrado, la austeridad en los hábitos del consumo, la moderación en la aspiración de las máximas prestaciones humanas. No son las virtudes heroicas de los griegos, pero siguen teniendo que ver, como en su caso, con la medida y el autodominio. Todas estas renuncias son exigibles en aras de la humanidad, un objetivo que nos obliga a ser responsables. Y es la posibilidad y la exigencia de ser responsables lo que nos está diciendo que somos libres. Biológicamente, la especie humana podría llegar a desaparecer, como han desaparecido tantas otras especies a lo largo del proceso evolutivo. No obstante, «sentimos, en el caso del hombre, que las cosas son de otra manera: sobre todo que él y lo que ha hecho no pueden desaparecer» ${ }^{17}$. No puede desaparecer una humanidad libre, ése es

\footnotetext{
${ }^{15}$ Ibid., pp. 102-103.

${ }^{16}$ Hans Jonas, El principio de responsabilidad, Barcelona, Herder, 1995, p. 40.

${ }^{17}$ Hans Jonas, Técnica, medicina y ética, Barcelona, Paidós, 1997, p. 53, y todo el capítulo 3.
} 
el primer valor que hay que conservar. Para que no desaparezca, sin embargo, lo que habrá que procurar es que esa humanidad tan libre que está abierta no sólo a la razón y a la sabiduría, sino a la sinrazón y a la demencia, haga un uso de la libertad que no sea contrario a su propia condición humana. Un uso responsable de la libertad. 